an inspector of schools at the Department of Education and Science with special responsibility for innovations in the school curriculum. He is a mathematician by training, and in recent months he has done much to convince British mathematicians to pay some attention to the teaching of their subject in the schools.

By all accounts, the demand for the services of CREDO is already substantial. The object is to use the experience of curriculum development acquired in Britain in recent years to assist curriculum development elsewhere. Everybody concerned with CREDO seems sensibly aware that it is not possible, and not desirable either, to foist educational experiments which suit Britain on countries overseas whose problems may be quite different, and that the best experiments are those which have roots in the countries that will eventually make use of them. The most immediate difficulty facing CREDO may be that countries in need of educational help may want to go faster, and seek promptly to introduce to Africa and elsewhere innovations now taking hold in educationally more advanced societies. Help of this kind naturally tends to be expensive. For the first three years CREDO has $£ 150,000$ in cash from the Nuffield Foundation, and $£ 50,000$ in kind from the Ministry of Overseas Development, but after the first meeting of the council one of its members was somewhat overawed that a single request from Nigeria for physics equipment exceeded the allocation in the first year's budget for purposes like these.

\section{Permanent Part-time}

THe belief that part-time teachers in British schools are more than an unfortunate necessity now seems to have been formulated by the Department of Education and Science. The Secretary of State, Mr. Anthony Crosland, said last week that "part-time teachers are not simply an invaluable aid in solving the short-term problem of teacher shortage". He went on to say that part-time teachers make it possible to construct more flexible time-tables for the schools, and described as "old-fashioned" the view that young children (in primary schools) need a measure of stability which can only be provided by a single teacher. In fact, the trend to part-time teaching is now quite rapid. In the past decade the number of part-time teachers has increased from 5,000 to nearly 40,000 and school administrators, like government officials, are hoping their number will continue to increase. It is true that teachers' organizations are conspicuously indifferent to this enthusiasm, but that is at least predictable. Indeed, teachers would probably be right in thinking that Mr. Crosland considers the trend to part-time teaching to be the thin end of a wedge that may eventually bring team teaching to British schools. Indeed, Mr. Crosland went so far last week as to say that part-time teaching suggests "greater flexibility in the employment of staff in school, so that teachers may become less confined to set periods and places, working much more on a team basis". In education, this is plain speaking.

\section{Heuristic Television}

Television has obviously a big part to play in science teaching, but how is it possible to prevent it being just another means of conveying too cut and dried a view of what science is like? This problem is perpetually perplexing. $\mathrm{ABC}$ television in Britain seems to have the beginnings of an answer. In a series of programmes beginning this autumn, and organized in collaboration with the Advisory Centre for Education--which also runs the National Extension College, a correspondence school-the company is aiming to cover the physics included in ordinary level examinations for the General Certificate of Education. At the same time it has put on sale a boxful of pieces of simple equipment and an instruction booklet to help participants in the course carry out some of the basic experiments which go to make up ordinary level physics. There are bits and pieces of springs and elastic, some splendid ceramic magnets, a wooden former for constructing home-made electrical machinery, and enough lenses to make some crude telescopes. It remains to be seen whether those who follow the course will be able to perform the ritual of verifying Boyle's Law. It is probably more important that the kit of bits and pieces lacks all measuring instruments except a simple wooden ruler and the materials for making crude balances with springs and beams.

The first lesson in the series, broadcast on September 25 , confirmed the impression created by the kit that the course is unlikely to be as thorough as most examiners would expect. That criticism, however, may well be unfair and is certainly irrelevant. Probably it is more significant that the first programme created no necessary connexion between the television screen and the experimental equipment. The ideal is that each programme should create such an intellectual climate that listeners have an incentive to worry away at their experimental equipment from one programme to the next. Even this, however, does not diminish the great interest of this innovation. Its real promise is of a way of combining mass television with education so as really to satisfy educational needs. There will be more people watching than those who want to pass in physics at ordinary level.

\section{Preprints made Outlaws}

THe Commission of Biochemical Editors of the International Union of Biochemistry is proposing to take firm and, it hopes, lethal steps against the Information Exchange Groups which have been organized, over the past four years, from the National Institutes of Health in the United States. At a meeting in Vienna a week ago, the editors of six principal journals agreed to propose to their editorial boards that in future they would not accept articles or other communications previously circulated through the Information Exchange Groups. Moreover, they decided that they would not allow papers accepted for publication to be circulated in the IEG system and that they would not allow reference to IEG memoranda except as "personal communications". Only the last of these three proposals will commend itself to the IEG organizers, for they too ask that the existence of their network shall be confidential. The first two recommendations could in themselves put IEG out of business. As yet it is too soon to know how quickly the six journals will be able to make a decision, but there are hopes that the matter will be resolved before the end of the year, by which time journals other than those represented at Vienna (including Nature) will be invited to declare themselves. 